\title{
Article
}

\section{Gd-Si Oxide Nanoparticles as Contrast Agents in Magnetic Resonance Imaging}

\author{
Alejandro Cabrera-García ${ }^{1}$, Alejandro Vidal-Moya ${ }^{1}$, Ángela Bernabeu ${ }^{2}$, Jesús Pacheco-Torres ${ }^{3}$, \\ Elisa Checa-Chavarria ${ }^{4}$, Eduardo Fernández ${ }^{4}$ and Pablo Botella ${ }^{1, *}$ \\ 1 Instituto de Tecnología Química, Universitat Politècnica de València-Consejo Superior \\ de Investigaciones Científicas, Avenida de los Naranjos s/n, 46022 Valencia, Spain; \\ alcabgar@itq.upv.es (A.C.-G.); svidal@itq.upv.es (A.V.-M.) \\ 2 Unit of Magnetic Resonance Imaging, Hospital Universitario de Alicante, INSCANNER S.L., Alicante, Spain; \\ angela.bernabeu@gmail.com \\ 3 Unit of Functional Magnetic Resonance Imaging, Instituto de Neurociencias (CSIC-UMH), Alicante, Spain; \\ jpacheco@umh.es \\ 4 Institute of Bioengineering, Universidad Miguel Hernández, Elche, Spain and Centre for Network \\ Biomedical Research (CIBER-BBN), Spain; echeca@goumh.umh.es (E.C.-C.); e.fernandez@umh.es (E.F.) \\ * Correspondence: pbotella@itq.upv.es; Tel.: +34-963-877-000 (ext. 78502); Fax: +34-963-879-444
}

Academic Editors: Eva Pellicer and Jordi Sort Viñas Received: 29 March 2016; Accepted: 27 May 2016; Published: 8 June 2016

\begin{abstract}
We describe the synthesis, characterization and application as contrast agents in magnetic resonance imaging of a novel type of magnetic nanoparticle based on Gd-Si oxide, which presents high $\mathrm{Gd}^{3+}$ atom density. For this purpose, we have used a Prussian Blue analogue as the sacrificial template by reacting with soluble silicate, obtaining particles with nanorod morphology and of small size $(75 \mathrm{~nm})$. These nanoparticles present good biocompatibility and higher longitudinal and transversal relaxivity values than commercial $\mathrm{Gd}^{3+}$ solutions, which significantly improves the sensitivity of in vivo magnetic resonance images.
\end{abstract}

Keywords: Prussian Blue analogues; Gd-Si nanoparticles; magnetic resonance imaging; contrast agent

\section{Introduction}

One of the main reasons why cancer is a major medical challenge of the 21st century is that, in many cases, therapy success is mostly affected by timely diagnosis and prognosis. In this sense, it is crucial to find novel approaches of diagnostic techniques capable of detecting the malignancy at early stages. Here, magnetic resonance imaging (MRI) is a non-invasive technique in medical research that presents several advantages (use of non-ionizing radiation, widespread clinical implementation, and good anatomical resolution) that make it one of the most powerful imaging techniques [1-3]. Contrast agents (CA) are used for multiple purposes in MRI, one of them being the clinical detection of tumors [4]. Based on their relaxation processes, CAs are classified as $T_{1}$-positive agents of paramagnetic species and $T_{2}$-negative agents of super-paramagnetic materials. Due to their high sensitivity and detectability, $\mathrm{Gd}^{3+}$-based soluble chelates are the most representative and preferential $T_{1} \mathrm{CAs}$ in current MRI clinical applications [5]. However, their poor pharmacokinetics profile, due to quick renal filtration, limits the sensitivity [6]. This, consequently, requires the administration of generous CA doses, e.g., perfusion studies for tumor detection, which may lead to some side effects such as headache, nausea, and dizziness [7]. Among the most significant side effects reported regarding the administration of $\mathrm{Gd}^{3+}$ compounds, we find nephrogenic systemic fibrosis in patients with impaired kidney function, hypersensitivity reactions, and nephrogenic fibrosing dermopathy, which makes it expedient to develop alternatives to these small, soluble molecules [8]. 
At this point, magnetic nanoparticles (MNP) present several advantages over conventional $\mathrm{Gd}^{3+}$ CAs, such as large payloads of paramagnetic metal ions, extended plasma circulating half-lives, passive accumulation at tumor sites, and improved safety profiles $[9,10]$. Therefore, the incorporation of $\mathrm{Gd}^{3+}$ in a stable nanocarrier points to the development of safe and efficient CAs for MRI. In this context, silica nanomaterials have been recently considered to be excellent candidates for the preparation of drug delivery systems and CAs. Firstly, their textural properties favor the loading of significant quantities of therapeutic molecules within pore channels. Secondly, it is possible to obtain nanoparticles of these materials, which results in an accurate control over pore structure, particle shape and size [11,12] and, finally, the silanol-containing surface can be easily functionalized, introducing additional features that allow imposing targeting delivery [13]. Furthermore, biocompatibility test results have shown the potential of these materials in the preparation of pharmaceutical forms that might find application in diagnostics and customized medicine [14].

The first attempt to create a silica-based $\mathrm{Gd}^{3+} \mathrm{CA}$ was by incorporation, by covalent bonding or by confinement, of a $\mathrm{Gd}^{3+}$ chelate [15-23]. This way, highly paramagnetic conjugates may be obtained, in some cases with very impressive longitudinal $\left(r_{1}\right)$ and transversal $\left(r_{2}\right)$ relaxivity values. However, $\mathrm{Gd}^{3+}$ concentration in these conjugates is usually low, which reduces the sensitivity for in vivo applications. Moreover, metal leaching in biological fluids is not always negligible, which may hinder administration of recurrent doses. More stable CAs can be prepared by doping the silica matrix with $\mathrm{Gd}^{3+}$ cations [24-29], but the paramagnetic center density in the silicate network remains limited. A possibility to increase the number of metal centers per particle and to avoid toxicity issues is to protect small gadolinium nanoparticles with a silica shell [30-37]. These systems are very stable in physiological medium and their main drawback is the low accessibility of the $\mathrm{Gd}^{3+}$ sites to water molecules, due to the confining effects developed over the silica coating. It must be considered that the $r_{1}$ relaxivity is highly dependent on the number of water molecules coordinating to each metal ion in the first hydration sphere (q), which plays a detrimental role in MRI properties of these materials, especially when the present trend in clinical MRI is moving towards the use of higher magnetic field strength to obtain a better signal to noise ratio (SNR).

In order to increase the number of metal centers per particle, without reducing the water accessibility, an alternative is to develop Gd silicate-based MNP, where the high ion density and a disordered structure allow for efficient interaction of most $\mathrm{Gd}^{3+}$ sites with the surrounding water [35]. On this basis, we introduce here a novel approach for the synthesis of Gd-Si oxide nanoparticles with high $\mathrm{Gd}^{3+}$ atom density and excellent stability in physiological conditions. For this purpose, we used an optimized method developed by our group [38], wherein Prussian Blue analogue (PBA) $\mathrm{Gd}\left(\mathrm{H}_{2} \mathrm{O}\right)_{4}\left[\mathrm{Fe}(\mathrm{CN})_{6}\right]$ is used as a sacrificial template by reacting with soluble silicate. By overlapping kinetics of silica condensation with $\left[\mathrm{Fe}(\mathrm{CN})_{6}\right]^{3-}$ removal, we are able to synthesize particles of an oxide nanocomposite with equal shape and size than former PBA crystallites. The resulting material presents nanorod morphology, small particle size (75 nm average length), and shows good $r_{1}$ and $r_{2}$ relaxivity values in a 3 tesla (T) magnetic field, improving positive contrast of in vitro and in vivo MRI images.

\section{Results and Discussion}

\subsection{Materials Preparation and Characterization}

Scheme 1 depicts the strategy to synthesize pre-formed Gd-Si oxide nanoparticles. Firstly, an improved method for the preparation of GdFe PBA with small particle size was developed. 


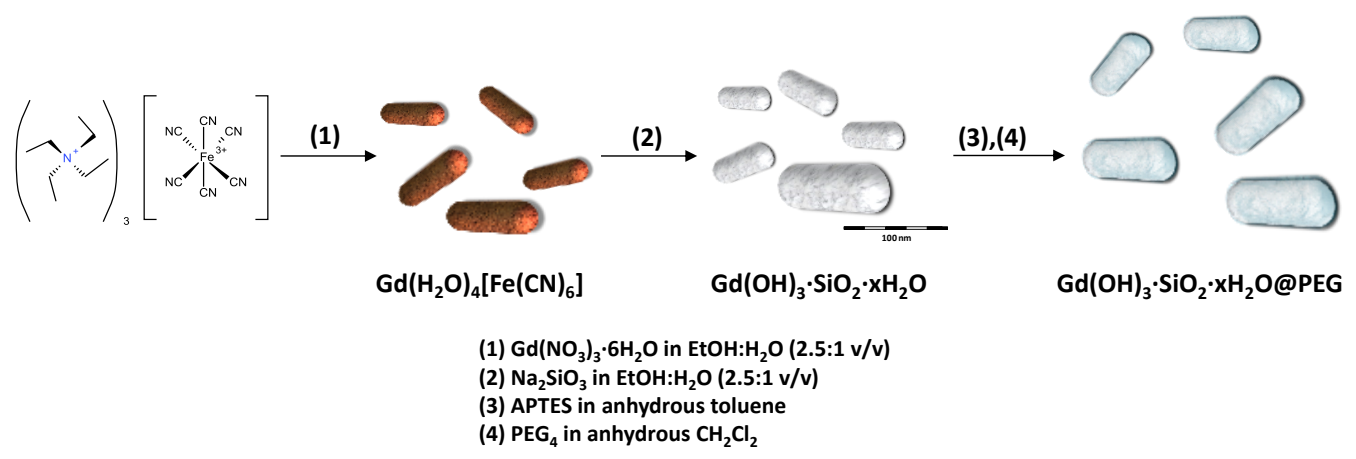

Scheme 1. Synthesis layout of $\mathrm{Gd}-\mathrm{Si}$ oxide nanorods using $\mathrm{Gd}\left(\mathrm{H}_{2} \mathrm{O}\right)_{4}\left[\mathrm{Fe}(\mathrm{CN})_{6}\right]$ as a sacrificial template.

Rod-shaped, monodispersed, high-purity particles of $94 \mathrm{~nm}$ average diameter were obtained (see Table 1). The crystal structure of the tridimensional coordination network $\mathrm{Gd}\left(\mathrm{H}_{2} \mathrm{O}\right)_{4}\left[\mathrm{Fe}(\mathrm{CN})_{6}\right]$ has been recently solved [39]. The solid crystallizes in the orthorhombic system with $C_{m c m}$ space group and cell parameter of $a=7.4016(3) \AA, b=12.78813(16) \AA$, and $c=13.5980(12) \AA$. This nanosized MOF presents a fully comparable powder X-ray diffraction (XRD) pattern to that obtained for the bulk compound (Figure 1). Moreover, crystal composition, as determined by energy-dispersive X-ray spectroscopy analysis (EDS) analysis, is very homogeneous, with uniform Fe and Gd distribution within the particles, as revealed by elemental mapping results (Figure 2), which is strongly consistent with the stoichiometry of the metal-organic framework (MOF).

Table 1. Compositional and textural characteristics of as-synthesized materials.

\begin{tabular}{|c|c|c|c|c|c|c|c|}
\hline \multirow{2}{*}{ Sample } & \multirow{2}{*}{ Molecular Formula } & \multicolumn{3}{|c|}{ Atomic Composition (\%) ${ }^{a}$} & \multicolumn{2}{|c|}{ Size (nm) } & \multirow{2}{*}{$\begin{array}{c}\text { Area BET } \\
\left(\mathrm{m}^{2} \cdot \mathrm{g}^{-1}\right)^{b}\end{array}$} \\
\hline & & Gd & $\mathrm{Fe}$ & Si & TEM $^{c}$ & $\mathrm{DLS}^{d}$ & \\
\hline $\mathrm{GdFe}$ & $\mathrm{Gd}\left(\mathrm{H}_{2} \mathrm{O}\right)_{4}\left[\mathrm{Fe}(\mathrm{CN})_{6}\right]$ & 52.8 & 47.2 & - & $94.2 \pm 35.5$ & $\mathrm{nd}^{e}$ & $\mathrm{nd}^{e}$ \\
\hline GdSi & $\mathrm{Gd}(\mathrm{OH})_{3} \cdot 3 \mathrm{SiO}_{2} \cdot x \mathrm{H}_{2} \mathrm{O}$ & 18.6 & 1.3 & 80.1 & $75.2 \pm 24.0$ & $84 \pm 44$ & 19.0 \\
\hline
\end{tabular}

${ }^{a}$ As determined from the energy-dispersive X-ray spectroscopy analysis (EDS) study; ${ }^{b}$ Brunauer-Emmett-Teller (BET) surface area analysis; ${ }^{c} \mathrm{Avg} \pm \mathrm{SD}$, as determined by transmission electron microscopy (TEM) measurement of at least 200 particles; ${ }^{d}$ Diffuse light scattering (DLS); ${ }^{e}$ nd $=$ not determined.

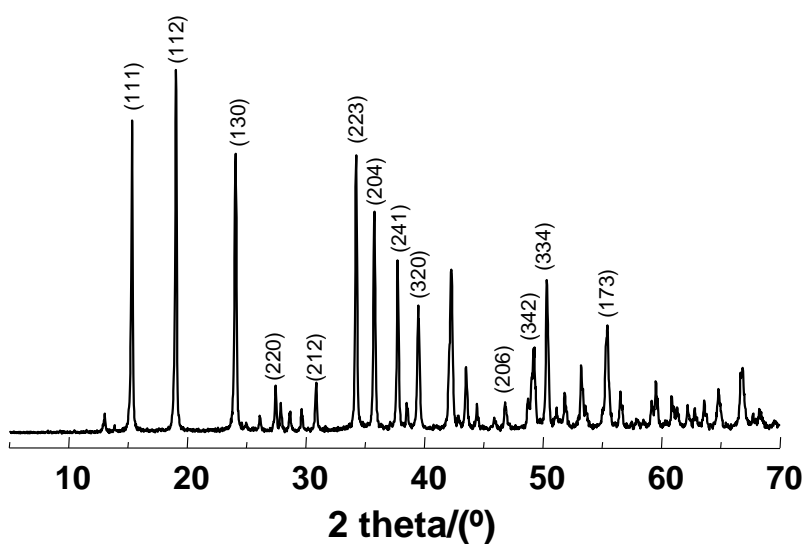

Figure 1. Powder X-ray diffraction (XRD) pattern of as-made GdFe nanorods. 

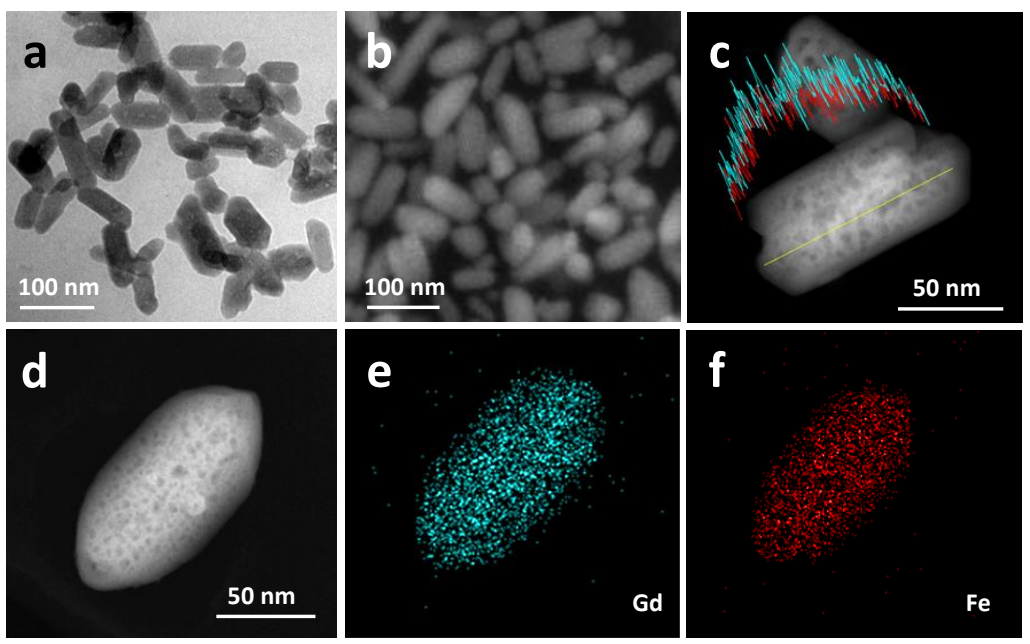

Figure 2. Electron microscopy study of as synthesized GdFe nanorods. (a,b): Transmission electron microscopy (TEM) (a) and field-emission scanning electronic microscopy (FESEM) (b) images; (c) Scanning transmission electron microscopy (STEM) image with energy-dispersive X-ray spectroscopy analysis (EDS) line scans. Legend: blue line = Gd; red line = Fe; $(\mathbf{d}, \mathbf{f})$ : STEM image $(\mathbf{d})$ and EDS mapping pictures of one GdFe nanorod $(\mathbf{e}, \mathbf{f})$.

Such GdFe small crystallites are partially soluble in neutral water, and an ion exchange reaction takes place in alkaline solution resulting in complete MOF dissolution, as follows Equation (1):

$$
\mathrm{Gd}\left(\mathrm{H}_{2} \mathrm{O}\right)_{4}\left[\mathrm{Fe}(\mathrm{CN})_{6}\right](\mathrm{s})+3 \mathrm{OH}^{-}(\mathrm{aq}) \leftrightarrow \mathrm{Gd}(\mathrm{OH})_{3}(\mathrm{~s})+\left[\mathrm{Fe}(\mathrm{CN})_{6}\right]^{3-}(\mathrm{aq})+4 \mathrm{H}_{2} \mathrm{O}
$$

This reaction can be carried out in the presence of silicate ions, the hydrolysis of which provides enough $\mathrm{OH}^{-}$concentration for the transformation. Therefore, under optimized conditions, it is possible to overlap ion exchange of the PBA with the hydrolysis of the conjugate base, and, as a consequence, a simultaneous and stoichiometric condensation of gadolinium hydroxide and silica takes place. This process is defined by Equation (2):

$$
\begin{aligned}
& 2 \mathrm{Gd}\left(\mathrm{H}_{2} \mathrm{O}\right)_{4}\left[\mathrm{Fe}(\mathrm{CN})_{6}\right](\mathrm{s})+3 \mathrm{SiO}_{3}{ }^{2-}(\mathrm{aq})+3(1+x) \mathrm{H}_{2} \mathrm{O} \\
\leftrightarrow & 2 \mathrm{Gd}(\mathrm{OH})_{3} \cdot 3 \mathrm{SiO}_{2} \cdot x \mathrm{H}_{2} \mathrm{O}(\mathrm{s})+2\left[\mathrm{Fe}(\mathrm{CN})_{6}\right]^{3-}(\mathrm{aq})+4 \mathrm{H}_{2} \mathrm{O}
\end{aligned}
$$

Dense, monodispersed Gd-Si oxide nanoparticles (GdSi) are obtained mostly preserving the original rod shape and size of the sacrificial GdFe crystals. The reaction proceeds slowly at room temperature in a silicate solution $\left(\mathrm{EtOH}: \mathrm{H}_{2} \mathrm{O}, 2.5: 1 \mathrm{v} / \mathrm{v}\right)$. This way, MOF particles are gradually consumed, releasing $\mathrm{Fe}(\mathrm{CN})_{6}{ }^{3-}$ as hydroxide ions diffuse inward, and a composite of $\mathrm{Gd}(\mathrm{OH})_{3}$ and $\mathrm{SiO}_{2}$ is formed. The powder XRD pattern shows an amorphous material (figure not shown), with BET surface area of about $19.0 \mathrm{~m}^{2} \cdot \mathrm{g}^{-1}$ and low porosity (Table 1). This nanohybrid low crystallinity is due to mutual inhibition of crystal growth between the highly-dispersed $\mathrm{Gd}(\mathrm{OH})_{3}$ and $\mathrm{SiO}_{2}$ [40].

Electron microscopy study by TEM and FESEM (Figure 3) confirms that morphology does not experience significant changes, although nanosized rods present a slightly smaller average diameter $(75 \mathrm{~nm})$. As already detected with other morphologies at the nanoscale [38], our transformed particles are fully dense, what contrasts with observations by Lou and co-workers over Prusian Blue microbox derivatives [40,41]. We attribute such different material features to the nanoscale, as the inward $\mathrm{OH}^{-}$ ion diffusion is faster in smaller particles and $2 \mathrm{Gd}(\mathrm{OH})_{3} \cdot 3 \mathrm{SiO}_{2} \cdot x \mathrm{H}_{2} \mathrm{O}$ moiety precipitates quickly to refill the empty space left by released $\left[\mathrm{Fe}(\mathrm{CN})_{6}\right]^{3-}$ species. EDS analysis is consistent with the expected stoichiometry (Gd:Si atomic ratio of about 2:3), and demonstrates almost complete iron removal (Table 1). Moreover, the spatial distribution of $\mathrm{Gd}(\mathrm{OH})_{3}$ and $\mathrm{SiO}_{2}$ in isolated particles can be 
clearly seen by elemental mapping (Figure 3c-h), which illustrates both the homogeneous distribution of $\mathrm{Gd}$ and $\mathrm{Si}$, and iron extraction.

The GdSi sample presents a good stability pattern for use in biological medium. In this context, the hydrodynamic diameter, as determined by diffuse light scattering (DLS) (Figure 4), is $83.9 \pm 44.1 \mathrm{~nm}$, is very close to that determined by TEM, and with a narrow size distribution, which indicates that most of the particles are monodispersed. Furthermore, dissolution tests carried out for $24 \mathrm{~h}$ in phosphate buffer saline (PBS) and in an isotonic glucose aqueous solution revealed no detectable leaching of $\mathrm{Gd}^{3+}$ and /or $\mathrm{Si}^{4+}$ cations in the incubation medium.
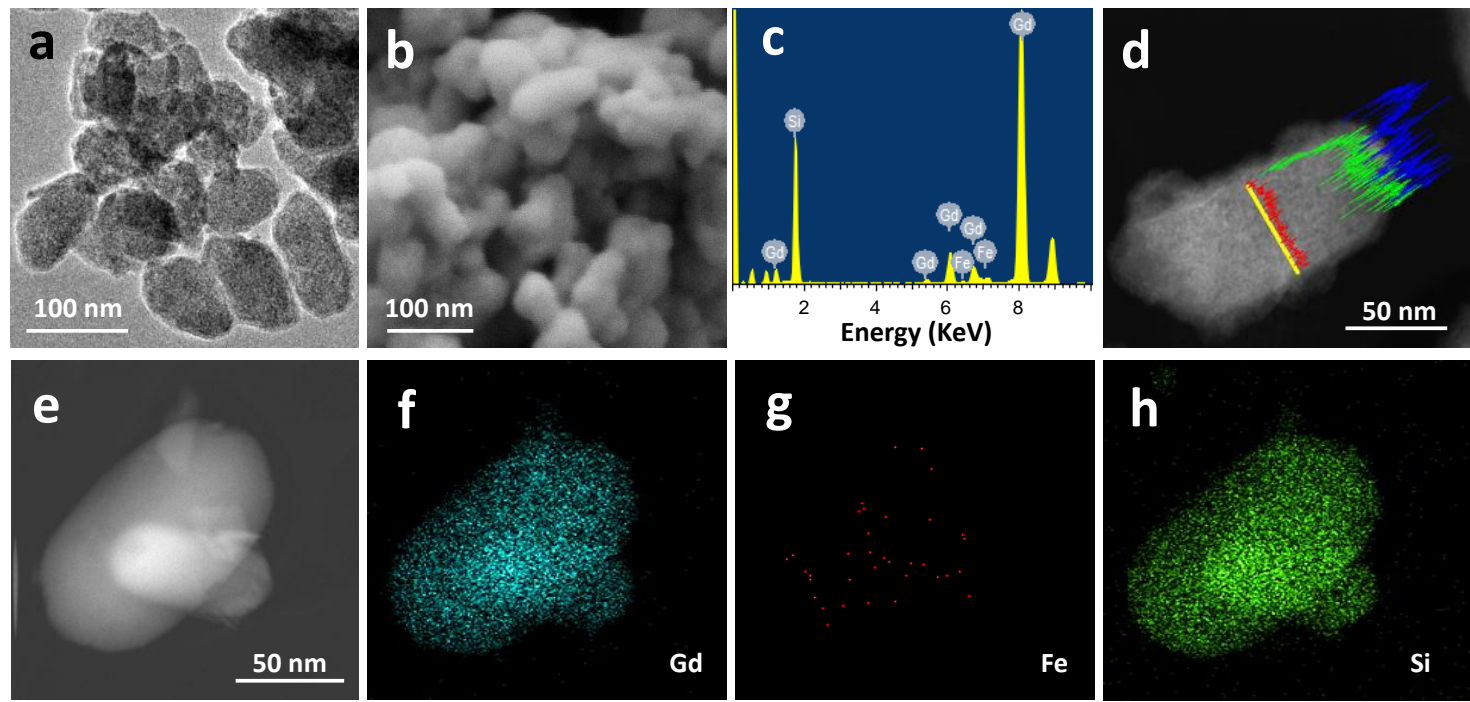

Figure 3. Electron microscopy study of GdSi nanorods obtained by alkaline transformation of GdFe precursor. (a,b): TEM (a) and FESEM (b) images of GdSi nanoparticles; (c) EDS elemental analysis; (d) STEM image with EDS line scans. Legend: blue line = Gd; red line = Fe; green line = Si; (e-h) STEM image (e) and EDS mapping pictures of two GdSi nanorods (f-h).

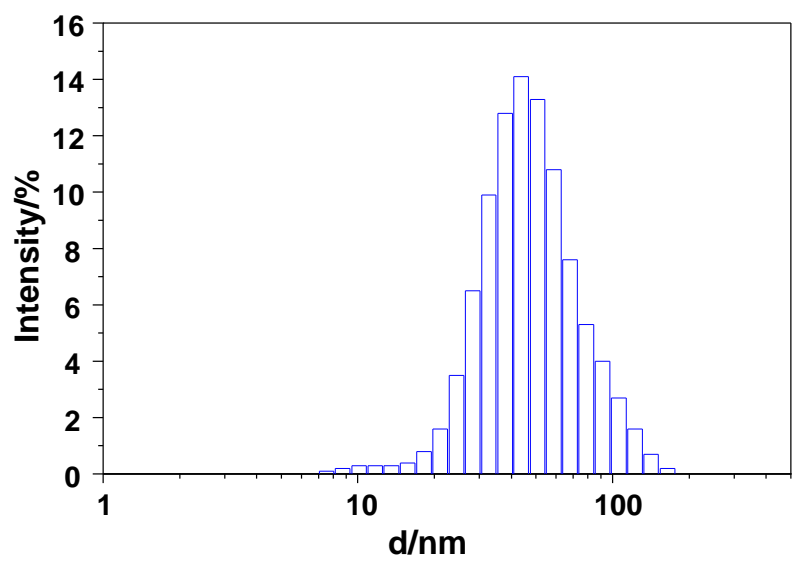

Figure 4. Particle hydrodynamic diameter of GdSi sample as determined in water by DLS.

\subsection{Relaxivity Measurements and In Vitro MRI}

The efficacy of GdSi as $T_{1}$ - or $T_{2}$-weighted CA for MRI was evaluated by measuring the longitudinal $\left(r_{1}\right)$ and transversal $\left(r_{2}\right)$ nuclear magnetic relaxation rates of water protons in aqueous suspensions at $3 \mathrm{~T}$ and room temperature. Stable colloids were prepared in aqueous xanthan gum 
$(0.1 \%)$ solution with $\mathrm{Gd}^{3+}$ concentration in the range $0-1.00 \mathrm{mM}$. Relaxivity values were determined by using the following expression [42]:

$$
\frac{1}{T_{i(w)}}=\frac{1}{T_{i(0)}}+r_{i}
$$

where $i=1$ or 2 values, respectively, for longitudinal or transversal-weighted effect of CA. $1 / T_{i(\mathrm{w})}$ is the global relaxation rate constant of bulk water molecules, $\mathrm{T}_{i(0)}$ is the water relaxation time without contrast agents (CA), and $C$ is the paramagnetic ion concentration. Therefore, $r_{1}$ and $r_{2}$ values were determined, respectively, from the plot slopes of $1 / T_{1}\left(\mathrm{~s}^{-1}\right)$ and $1 / T_{2}\left(\mathrm{~s}^{-1}\right)$ versus $\mathrm{Gd}^{3+}$ concentration (mM, Table 2 and Figure 5). For the sake of comparison, same measurements were carried out with commercial CA gadopentetate dihydrogen salt (Gd-DTPA, Aldrich). CAs can be classified according to their $T_{1}$ or $T_{2}$ lowering activity. Moreover, when $r_{2} / r_{1}$ value is close to 1 , application as a positive (bright) CA is favored, whereas if this ratio increases far from 1 the CA works better for negative (dark) contrast [43].

Table 2. Relaxivity properties for sample GdSi sample and commercial gadopentetate dihydrogen salt (Gd-DTPA).

\begin{tabular}{cccc}
\hline Sample & $r_{\mathbf{1}} / \mathbf{s}^{-\mathbf{1}} \cdot \mathbf{m M}^{-\mathbf{1}}$ & $\boldsymbol{r}_{\mathbf{2}} / \mathbf{s}^{\mathbf{- 1}} \cdot \mathbf{m M}^{-\mathbf{1}}$ & $r_{\mathbf{2}} / \mathbf{r}_{\mathbf{1}}$ \\
\hline GdSi & 5.6 & 8.2 & 1.4 \\
Gd-DTPA & 4.1 & 3.3 & 0.8 \\
\hline
\end{tabular}
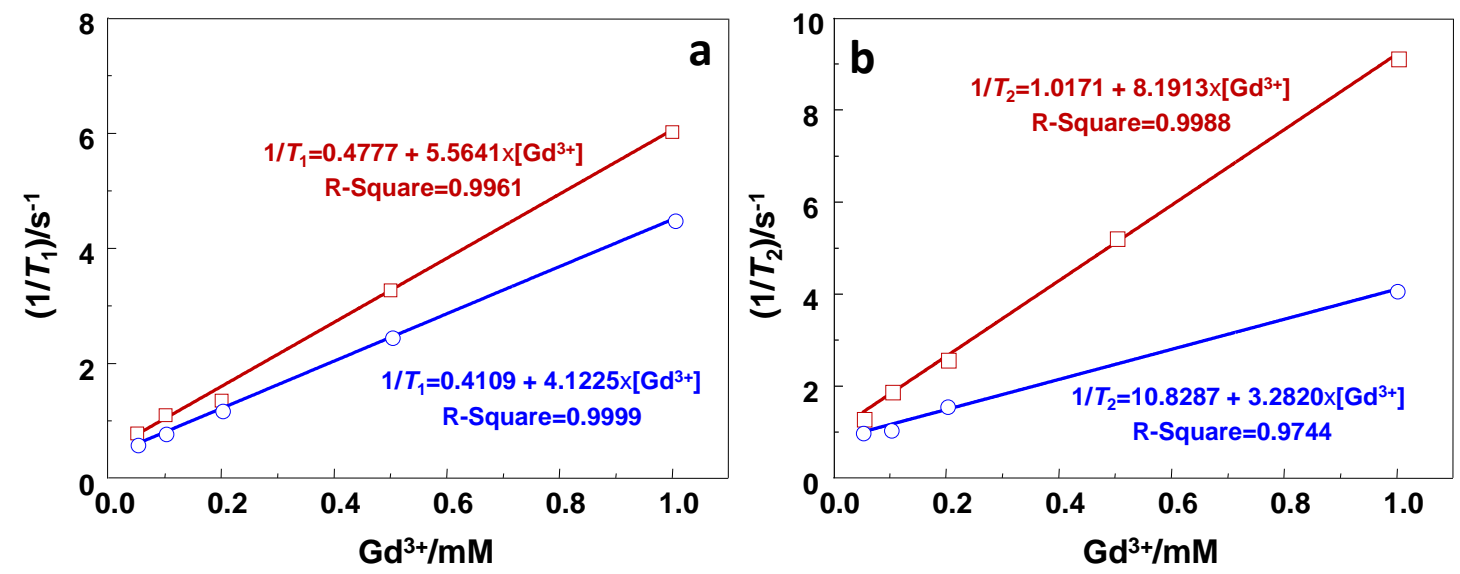

Figure 5. $T_{1}(\mathbf{a})$ and $T_{2}(\mathbf{b})$ relaxation rate measurements vs concentration of GdSi aqueous solutions (0.1\% xanthan gum) at a magnetic field of 3 T. Legend: (॰) GdSi; (०) Gd-DTPA.

As it can be seen in Table 2, GdSi sample shows longitudinal and transversal relaxivity values, respectively, 1.4 and 2.5 times higher than those corresponding to the soluble $\mathrm{Gd}^{3+}$ complex. This is in agreement with other authors' observations for different Gd silicate nanoparticles [37]. At this point, the high Gd concentration $(320 \mathrm{mg} / \mathrm{g}$ ) present in this material should be considered. With regards to the mononuclear $\mathrm{Gd}^{3+}$ complex, such a large density of paramagnetic centers in the nanoparticle shortens $T_{1}$ and $T_{2}$ scores due to a cooperative effect and accessibility of all $\mathrm{Gd}^{3+}$ centers (surface and core) [39]. Therefore, it is noticeable that no diffusion restrictions are present between water molecules and $\mathrm{Gd}^{3+}$ sites located in the silicate matrix. Additionally, it must be taken into account that the presence of a small $\mathrm{Fe}^{3+}$ quantity in the as-synthesized GdSi sample (Table 1) might contribute to a reduced $T_{2}$ value. In this sense, with a $r_{2} / r_{1}$ ratio of about 1.5 , this material is expected to improve MRI images mostly in positive contrast. To further check the capability of the GdSi nanomaterial, we collected phantom MRI images (Figure 6). The phantom was scanned with a single slice in coronal orientation with variable CA or gadopentetate concentration. Results show that $T_{1}$ images become 
progressively brighter as nanoparticle content increases (Figure 6a,b). Furthermore, $T_{2}$-weighted images become darker with $\mathrm{Gd}^{3+}$ concentration, but with lower significance than the positive contrast (Figure 6c). In all cases, the sensitivity of this system is higher than that of the commercial $\mathrm{Gd}^{3+}$ chelate. This encouraged us to test these MNPs in biological conditions, as described in the next two sections.

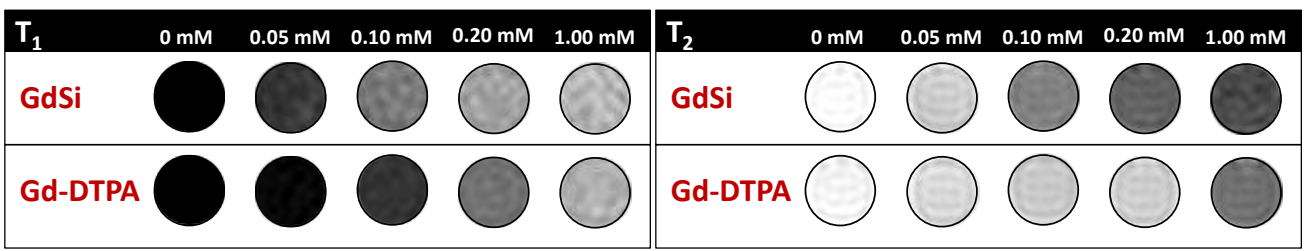

Figure 6. $T_{1}$-weighted (left) and $T_{2}$-weighted (right) magnetic resonance imaging (MRI) slices of GdSi aqueous solutions $\left(0.1 \%\right.$ xanthan gum), with varying $\mathrm{Gd}^{3+}$ concentration, at magnetic field of $3 \mathrm{~T}$ and echo time of $2 \mathrm{~ms}\left(T_{1}\right)$ and $203 \mathrm{~ms}\left(T_{2}\right)$.

\subsection{Cytotoxicity Test}

In order to validate the potential performance of the Gd-Si nanoparticles in a biological environment, cell viability was assessed $24 \mathrm{~h}$ after incubation with the GdSi sample by measuring the conversion of 3-(4,5-dimethylthiazol-2-yl)-2,5-diphenyltetrazolium bromide (MTT) to its formazan form following standard procedures. For these experiments we used healthy fibroblasts (3T3 cell line) and several cancer cell lines (HeLa cells, 42-MG-BA glioblastoma multiforme cells and SH-SY5Y neuroblastoma cells) at a range of concentrations $\left(0.25-100 \mu \mathrm{g} \cdot \mathrm{mL}^{-1}\right)$. Results (Figure 7) indicate that cell survival was always of about $70 \%$ or higher, even at maximum particle concentration. Despite MTT assay limitations for accurate cell viability determination, these results correspond to an acceptable biocompatibility profile.

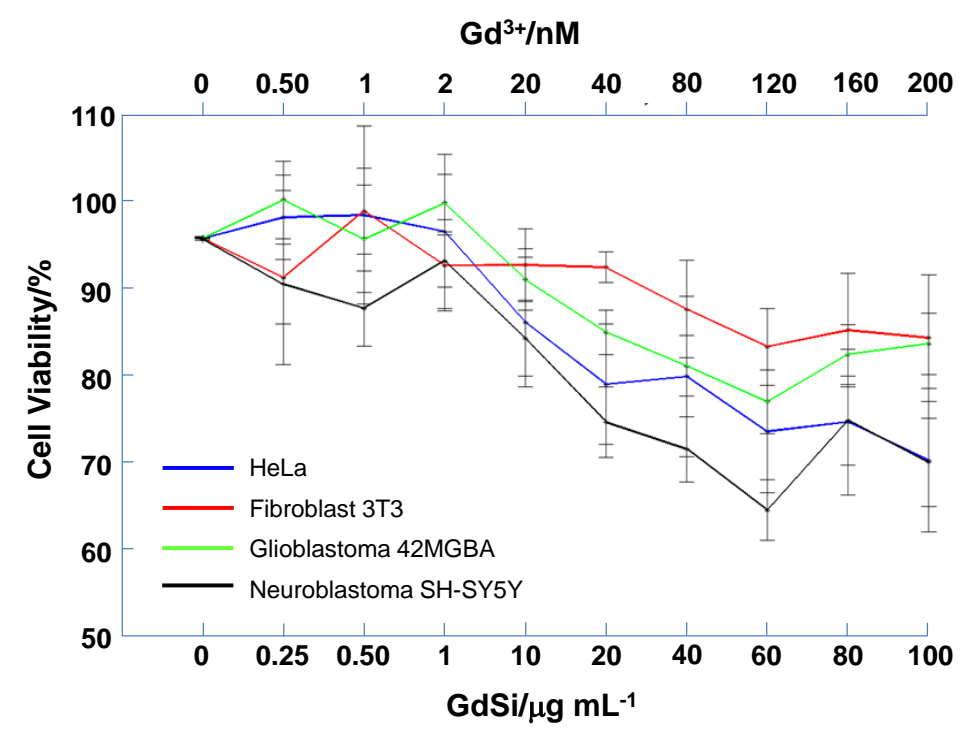

Figure 7. In vitro 3-(4,5-dimethylthiazol-2-yl)-2,5-diphenyltetrazolium bromide (MTT) cell viability assays in different cell lines incubated with variable concentrations of GdSi magnetic nanorods (mean $\pm \mathrm{SEM}, n=4)$. Top $X$-axis indicates the concentration of equivalent $\mathrm{Gd}^{3+}$.

\subsection{In Vivo MRI Studies Imaging}

It is well known that when introducing non-protected nanoparticles in blood, these suffer from strong protein adsorption, resulting in protein corona formation, which promotes further interaction with cell elements of the reticuloendothelial system (RES) [44]. As a consequence, particles are 
rapidly cleared from blood and accumulated in RES tissues, mainly the liver, spleen, and lungs. Consequently, for the in vivo study of GdSi contrast material, we firstly modified nanorod surfaces with a short polyethyleneglycol (PEG) chain, according to a recipe developed by our group [45]. This way, nanoparticles are expected to prolong circulation in the blood stream, finally being removed from the body mostly by renal (urine) and hepatic (biliary) routes [46,47]. Then, $1.0 \mathrm{~mL}$ of a $5 \mathrm{mg} \cdot \mathrm{mL}^{-1}$ GdSi $_{\text {PEG }}$ stable colloid in glucose $5.5 \%$ was perfused into the catheterized tail vein of healthy male Sprague-Dawley rats as a bolus $\left(0.04 \mathrm{mmol} \mathrm{Gd} \mathrm{kg}{ }^{-1}\right)$. Subsequently, $T_{1}$ - and $T_{2}$-weighted images were acquired before (baseline) and after the administration of the CA by using a $7 \mathrm{~T}$ horizontal scanner.

Figure 8 shows coronal $T_{1}$-weighted images depicting kidneys (Figure $8 \mathrm{a}, \mathrm{b}$, red arrows) and liver (Figure 8c,d, red arrows), respectively, before (Figure 8a,c) and after (Figure 8b,d) CA administration. These organs receive most of the blood stream showing highly significant particle accumulation, which promotes a noticeable MRI $T_{1}$ contrast enhancement. Kidneys showed a $7 \%$ increase in the MRI signal intensity (SI) after the CA administration. Liver presented non-homogenous changes, probably due to restricted nanoparticle biodistribution and pharmacokinetics, with some areas depicting large changes up to $21 \%$ (Figure $8 \mathrm{c}, \mathrm{d}$, arrowhead), whereas other areas showed no changes or even a decrease in SI. The contrast enhancement in the liver stands for at least one hour, the time we followed the contrast agent by MRI. We can hypothesize that contrast will be enhanced for longer because when we stopped the acquisition we were still able to detect a signal intensity enhancement with respect to baseline.

We are aware that similar MRI $T_{1}$ contrast increase has also been recently reported with other paramagnetic nanoparticles [48,49]. However, the GdSi system shows improved stability and a superior safety profile in biological fluids, as no cation leaching was observed in dissolution tests carried out for $24 \mathrm{~h}$. Moreover, although this is not the aim of this work, in the case of application to tumor development study, GdSi nanoparticle delivery to cancer cells may be promoted by surface incorporation of specific moieties that target upregulated peptides in rapidly-dividing cells [50].

Conversely, despite the good MRI in vitro results formerly presented for $T_{1}$, we must say that no significant change was observed in $T_{2}$ weighted images following CA administration.
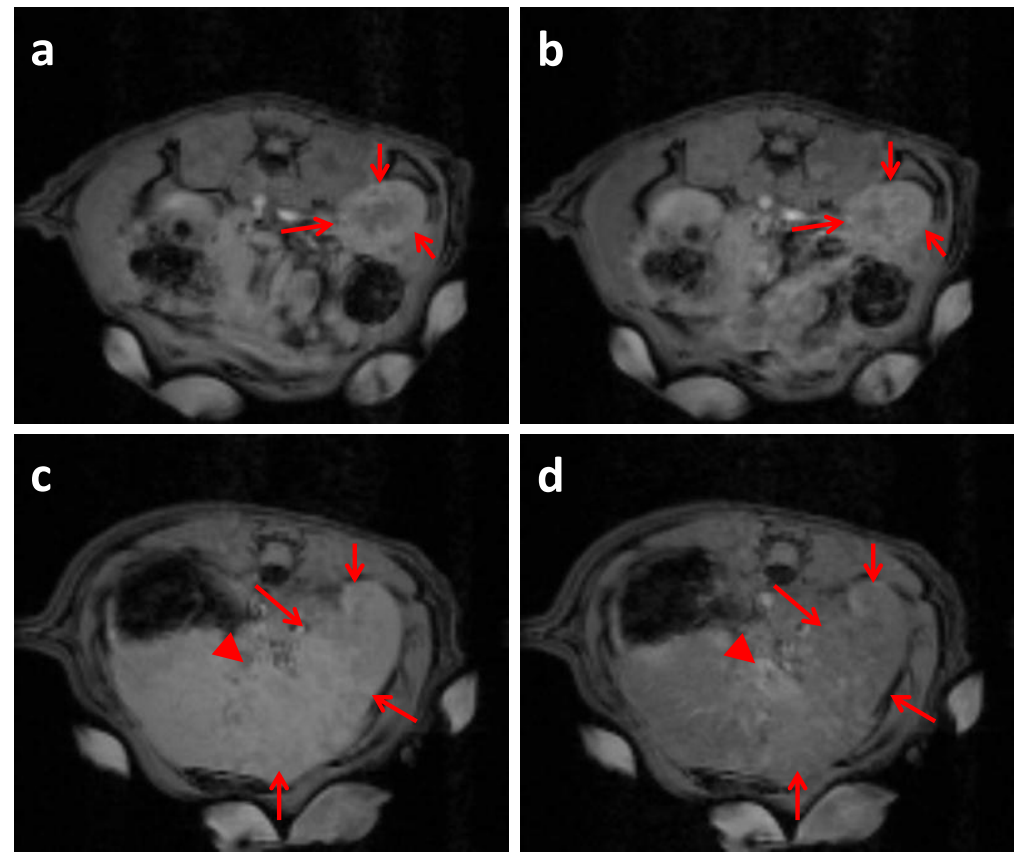

Figure 8. In vivo coronal $T_{1}$-weighted images acquired from a male Sprague-Dawley rat at $7 \mathrm{~T}$ magnetic field. (a,c) Control (baseline) with no MNP administration; (b,d) Acquisition $30 \mathrm{~min}$ after GdSi nanoparticles injection $\left(0.04 \mathrm{mmol} \mathrm{Gd}^{3+} \mathrm{kg}^{-1}\right)$; Red lines show up kidneys $(\mathbf{a}, \mathbf{b})$ and liver $(\mathbf{c}, \mathbf{d})$. 


\section{Experimental Section}

\subsection{Materials}

All reagents were purchased from Sigma-Aldrich (St. Louis, MO, USA), except $\mathrm{Gd}\left(\mathrm{NO}_{3}\right)_{3} \cdot 6 \mathrm{H}_{2} \mathrm{O}$ (ABCR, Karlsruhe, Germany) and HPLC grade solvents (Scharlab, Barcelona, Spain). Gd-Si oxide nanoparticles protected with a PEG external coating were synthesized in a three-step process (Figure 1).

HeLa cell line, D6-3T3 (fibroblasts cells), 42-MG-BA (glioblastoma multiforme cells), and SH-SY5Y (neuroblastoma cells), were purchased from the German Collection of Microorganisms and Cell Cultures, Braunschweig, Germany. Reagents used for cells growth were MEM Eagle, RPMI Medium 1640, DMEM, and Ham (F12) Nut MIX (Gibco BRL-Life Technologies, CA, USA) fetalbovine serum (FBS), and penicillin/streptomycin solution (Pen-Strep). Dimethyl sulfoxide (DMSO) and 3-(4,5-dimethylthiazol-2-yl)-2,5-diphenyltetrazoliumbromide (MTT) were purchased from Sigma-Aldrich (St. Louis, MO, USA).

Male Sprague-Dawley rats (250-300 g) (three specimens) were acquired from Janvier Labs (France) and maintained under a 12/12-h light/dark cycle (lights on 07:00-19:00 h) at room temperature $\left(22 \pm 2{ }^{\circ} \mathrm{C}\right)$, with free access to food and water. Rats were housed in group and adapted to these conditions for at least one week before experimental manipulation. All experiments were approved by the local authorities (CSIC-UMH) and were performed in accordance with Spanish (law 32/2007) and European regulations (EU directive 86/609, EU decree 2001-486).

\subsection{Synthesis of $\mathrm{Gd}\left(\mathrm{H}_{2} \mathrm{O}\right)_{4}\left[\mathrm{Fe}(\mathrm{CN})_{6}\right]$}

Firstly, we prepared the $\left(\mathrm{Et}_{4} \mathrm{~N}\right)_{3}\left[\mathrm{Fe}(\mathrm{CN})_{6}\right]$ precursor following a known recipe [51]. Briefly, $3.3 \mathrm{~g}$ $(10 \mathrm{mmol})$ of $\mathrm{K}_{3}\left[\mathrm{Fe}(\mathrm{CN})_{6}\right]$ and $6.3 \mathrm{~g}(30 \mathrm{mmol})$ of $\mathrm{Et}_{4} \mathrm{NBr}$ were dissolved with $200 \mathrm{~mL}$ of methanol in a $500 \mathrm{~mL}$ flask connected to a nitrogen line, and stirred at $30{ }^{\circ} \mathrm{C}$ for three days under $\mathrm{N}_{2}$ atmosphere. The mixture was filtered off and the filtrate was concentrated to approximately $10 \mathrm{~mL}$ by rotary evaporation. The resulting solution was stirred with $100 \mathrm{~mL}$ of ethyl ether and the yellow precipitate was collected by filtration. The crude was dissolved in $150 \mathrm{~mL}$ of refluxing acetonitrile and the solution was allowed to cool, obtaining $\left(\mathrm{Et}_{4} \mathrm{~N}\right)_{3}\left[\mathrm{Fe}(\mathrm{CN})_{6}\right]$. For nanosized Prussian Blue analogue preparation, $\mathrm{Gd}\left(\mathrm{NO}_{3}\right)_{3} \cdot 6 \mathrm{H}_{2} \mathrm{O}(0.86 \mathrm{~g}, 2.5 \mathrm{mmol})$ were dissolved in $50 \mathrm{~mL}$ of EtOH: $\mathrm{H}_{2} \mathrm{O}(2.5: 1 \mathrm{v} / \mathrm{v})$. Then, a solution of the previously-synthesized $\left(\mathrm{Et}_{4} \mathrm{~N}\right)_{3}\left[\mathrm{Fe}(\mathrm{CN})_{6}\right](1.5 \mathrm{~g}, 2.5 \mathrm{mmol}$, in $15 \mathrm{~mL}$ methanol) was added and the mixture was left for a day at room temperature. The precipitate was filtered off, washed with ethanol, and vacuum dried to yield $118 \mathrm{mg}$ of an orange powder (GdFe).

\subsection{Synthesis of GdSi Oxide/hydroxide Nanocomposite}

Dense, $\mathrm{Gd}(\mathrm{OH})_{3} \cdot 3 \mathrm{SiO}_{2} \cdot x \mathrm{H}_{2} \mathrm{O}$ nanoparticles $(\mathrm{GdSi})$ were prepared by modification of a previously reported method [40,41]. $\mathrm{Gd}\left(\mathrm{H}_{2} \mathrm{O}\right)_{4}\left[\mathrm{Fe}(\mathrm{CN})_{6}\right](550 \mathrm{mg}, 1.25 \mathrm{mmol})$, was suspended in $278 \mathrm{~mL}$ of EtOH: $\mathrm{H}_{2} \mathrm{O}(2.5: 1 v / v)$ with vigorous stirring. Then, 3-cyanopropiltrichlorosilane $(697 \mu \mathrm{L}, 4.50 \mathrm{mmol})$ was added and, after $30 \mathrm{~min}, 3.5 \mathrm{~mL}$ ammonia solution and $11 \mathrm{~mL}$ of sodium silicate solution $(0.54 \%$ $\mathrm{SiO}_{2}, 2.69 \mathrm{mmol}$ ) were introduced. The reaction was allowed to proceed for $48 \mathrm{~h}$. Non-reacted silicate ions were removed by subsequent centrifugation $(484 \mathrm{~g}, 2 \mathrm{~h})$, and the obtained white solid was washed repeatedly with milliQ water, centrifuged again $(1935 \mathrm{~g}, 30 \mathrm{~min})$, and further freeze dried $\left(-55^{\circ} \mathrm{C}\right.$, $16 \mathrm{~h})$.

In order to modify the GdSi surface, we used a method previously described by our group [45]. $375 \mathrm{mg}$ of $\mathrm{Gd}(\mathrm{OH})_{3} \cdot 3 \mathrm{SiO}_{2} \cdot x \mathrm{H}_{2} \mathrm{O}$ was dried at $80{ }^{\circ} \mathrm{C}$ and vacuum (8 torr) for $24 \mathrm{~h}$. Afterwards, $7.4 \mathrm{~mL}$ of anhydrous toluene was added and the mixture was heated to reflux. Then, $728 \mu \mathrm{L}(3.13 \mathrm{mmol})$ of 3-aminopropyltriethoxysilane (APTES) was added and the mixture was stirred for $3 \mathrm{~h}$. The obtained product was filtered off, washed with toluene and methanol and freeze-dried $\left(-55{ }^{\circ} \mathrm{C}, 16 \mathrm{~h}\right)$. Next, $156 \mathrm{mg}$ of the above material was suspended in $15.6 \mathrm{~mL}$ of anhydrous dichlorometane. Then, $195 \mu \mathrm{L}$ of diisopropyl amine were injected under nitrogen atmosphere. Afterwards, $234 \mathrm{mg}$ of 2,5,8,11-tetraoxatetradecan-14-oic acid succinimidyl ester $\left(\mathrm{PEG}_{4}\right)$ was added. The reaction was 
stirred overnight at room temperature. Later, the solvent was removed under reduced pressure and the nanoparticles were suspended in $100 \mathrm{~mL}$ of ethanol with stirring. Subsequently, the suspension was filtered off and washed with ethanol $(300 \mathrm{~mL})$. Finally, the material (GdSi $\left.\mathrm{PEG}_{\text {( }}\right)$ was freeze-dried $\left(-55^{\circ} \mathrm{C}, 16 \mathrm{~h}\right)$.

\subsection{Materials Characterization}

Powder X-ray diffraction (XRD) patterns were collected in a Philips X'Pert diffractometer equipped with a graphite monochromator, operating at $40 \mathrm{kV}$ and $45 \mathrm{~mA}$ and using nickel-filtered $\mathrm{Cu} \mathrm{K} \alpha$ radiation $(\lambda=0.1542 \mathrm{~nm})$. Liquid nitrogen adsorption isotherms of $200 \mathrm{mg}$ of sample were measured in a Micromeritics Flowsorb apparatus. Surface area calculations were done by the BET method. Samples for transmission electron microscopy (TEM) were ultrasonically dispersed in a mixture of EtOH: $\mathrm{H}_{2} \mathrm{O}(2.5: 1 \mathrm{v} / \mathrm{v})$ and transferred to carbon-coated copper grids. TEM and scanning transmission electron microscopy (STEM) micrographs were collected in a JEOL JEM 2100F microscope operating at $200 \mathrm{kV}$. The quantitative energy-dispersive X-ray spectroscopy analysis (EDS) was performed in an INCA Energy TEM 250 system from Oxford Instruments, working with a SDD X-MAX 80 detector. Field-emission scanning electron microscopy (FESEM) micrographs were collected in a ZEISS Ultra 55 microscope operating at $2 \mathrm{kV}$, with a $2 \times 10^{-9}$ A beam current and $2.5 \mathrm{~mm}$ as the working distance. Infrared spectra were recorded at room temperature in the 400-3900 $\mathrm{cm}^{-1}$ region with a Nicolet 205xB spectrophotometer, equipped with a Data Station, at a spectral resolution of $1 \mathrm{~cm}^{-1}$ and accumulations of 128 scans. Samples were outgassed at $400{ }^{\circ} \mathrm{C}$ under vacuum during $1 \mathrm{~h}$ for complete water removal before acquisition. Finally, water and organic $\left(\mathrm{PEG}_{3}\right)$ content were calculated from elemental analysis (FISONS, EA 1108 CHNS-O) and thermogravimetric (TGA) measurements (Mettler-Toledo TGA/SDTA851e).

\subsection{Stability Assays}

GdSi $i_{\text {PEG }}$ material stability in physiological medium was monitored by solution assay in phosphate-buffered saline (PBS, $1 \times$ ) or glucose aqueous solution ( $5.5 \mathrm{wt}$. \%). $5 \mathrm{mg}$ of the corresponding material were stirred in $1 \mathrm{~mL}$ at $1500 \mathrm{rpm}$ and $37^{\circ} \mathrm{C}$ in a Thermomixer ${ }^{\circledR}$ for $24 \mathrm{~h}$. Then, samples were centrifuged $(16,100 \mathrm{~g}, 15 \mathrm{~min})$ and supernatant metal cation concentration was analyzed by inducted couple plasma (ICP).

\subsection{Cell Biocompatibility}

The different cell lines were cultured in 96-well cell culture plates with the seeding densities shown below in a final medium volume of $200 \mu \mathrm{L} /$ well: HeLa 10,000 cells/mL; fibroblast 3T3 and glioblastoma 42-MGBA 50,000 cells / mL and neuroblastoma SH-SY5Y 100,000 cells/mL. HeLa cells were grown in MEM (Earle's), 3T3 cell line in DMEM, 42-MGBA cell line in MEM (Earle's) and RPMI 1640 (1:1), and SH-SY5Y cell line was cultured in a DMEM and Ham (F12) Nut MIX (1:1). Cell media were supplemented with 10\% FBS and Pen-Strep 1:100 $(v / v)$. The plates were cultured $24 \mathrm{~h}$ at $37^{\circ} \mathrm{C}$ and $5 \% \mathrm{CO}_{2}$ injection in air. After $24 \mathrm{~h}$ cells were treated with the $\mathrm{CA}$ at a concentration range of about $0.25-100 \mu \mathrm{g} / \mathrm{mL}$ in RPMI medium. Cells with nanoparticles were incubated at $37^{\circ} \mathrm{C}$ for $24 \mathrm{~h}$ and $5 \% \mathrm{CO}_{2}$. All concentrations were tested in triplicate and negative controls with no nanoparticles were also carried out.

Cell viability was measured using the 3-(4,5-Dimethylthiazol-2-yl)-2,5-diphenyltetrazolium bromide (MTT) assay. Briefly, $200 \mu \mathrm{L} /$ well of MTT/PBS $(1 \mathrm{mg} / \mathrm{mL})$ were added and the plates were incubated at $37^{\circ} \mathrm{C}$ for $3 \mathrm{~h}$. Formazan crystals were dissolved with $100 \mu \mathrm{L}$ DMSO and then absorbance at $595 \mathrm{~nm}$ was measured with a 1681130 iMark $^{\mathrm{TM}}$ Microplate Reader. Absorbance values were normalized with respect to the control and expressed in percentage using the next Equation (4):

$$
\text { Relative cell viability }=\frac{O D_{595} \text { TEST SAMPLE }}{O D_{595 \text { CONTROL }}} \times 100
$$


Data statistical analysis was performed applying arithmetic's means and error bars of statistical error means (SEM) using MATLAB (MathWorks).

\section{7. ${ }^{1} H$ NMR Relaxometry Study and In Vitro MRI.}

Relaxivity determinations and MRI studies were carried out in a clinical 3 T MRI unit (Philips Achieva 3 T X-Series; Philips Healthcare, The Netherlands) with an eight-channel phased array head coil. The phantom was scanned with a single slice in the coronal orientation, obtaining a transversal view of all tubes filled with variable CA concentration. Geometric parameters remain equivalent between the $T_{2}$ and $T_{1}$ estimation sequences (field of view $220 \times 220 \mathrm{~mm}^{2}$, slice thickness $5 \mathrm{~mm}$ and $1.0 \times 1.0 \mathrm{~mm}^{2}$ in plane resolution) sharing the same spatial localization. A multi-echo spin echo sequence was used to estimate $T_{2}$ values acquiring 32 echoes ranging from 14 to $231 \mathrm{~ms}(\Delta T E=7 \mathrm{~ms})$ with a sequence $T R$ of $2000 \mathrm{~ms}$. $T_{1}$ values of each tube were estimated using a look-locker inversion recovery acquisition with 107 inversion times ranging from 6.51-5306.51 ms, with an inversion time interval of $50 \mathrm{~ms}$. A new inversion pulse was applied every $6 \mathrm{~s}$ to avoid signal saturation due to extremely close inversion pulses. To reduce the influence of readout excitation pulse in the final $T_{1}$ values, an excitation flip angle of $5^{\circ}$ was applied during the TFE shot [47]. With regards to image analysis, $T_{2}$ maps were generated by nonlinear fitting of the signal acquired at every $T E$ to a mono-exponential model. The same procedure was applied to every image pixel producing $T_{2}$ maps. Moreover, $T_{1}$ maps were generated by nonlinear fitting of the signal acquired at every inversion time to the signal model described at [52]. As in the case of $T_{2}$ maps, the same procedure was applied to every image pixel to generate the final $T_{1}$ map. Quantitative values were obtained in aqueous xanthan gum $(0.1 \%)$ nanoparticle suspensions by manual region of interest (ROI) analysis over $T_{2}$ and $T_{1}$ maps. A circular ROI was placed for each tube, avoiding the border. In each ROI, means and standard deviations were computed for further comparison. The resulting $T_{1}$ and $T_{2}$ values were averaged and plotted as $1 / T_{i}\left(\mathrm{~s}^{-1}\right)$ where $i=1,2$ versus $\left[\mathrm{Gd}^{3+}\right](\mathrm{mM})$, the slopes of these graphs provided the specific relaxivities $r_{1}$ and $r_{2}$.

\subsection{In Vivo MRI Studies Imaging}

Rats were anesthetized in an induction chamber with 3\%-4\% isofluorane in medical air (0.8-1 L/min) and maintained with 1\%-2\% isofluorane (IsoFlo) during the MRI experiment. Anesthetized animals were taped down in a custom-made animal holder to minimize breathing-related movement artifacts. The body temperature was kept at $37{ }^{\circ} \mathrm{C}$ using a water blanket and animals were monitored using a MRI-compatible temperature control unit (MultiSens Signal conditioner, OpSens, Quebec, Canada). The breathing rate was also measured using a custom designed device. Experiments were carried out in a horizontal $7 \mathrm{~T}$ scanner with a $30 \mathrm{~cm}$ diameter bore (Biospec 70/30v, Bruker Medical, Ettlingen, Germany). The system had a $675 \mathrm{mT} / \mathrm{m}$ actively-shielded gradient coil (Bruker, BGA 12-S) of $11.4 \mathrm{~cm}$ inner diameter. $\mathrm{A}{ }^{1} \mathrm{H}$ rat body receive-transmitter resonator (Bruker BioSpin MRI GmbH, Germany) was employed. Data were acquired with a Hewlett-Packard console running Paravision software (Bruker Medical GmbH, Ettlingen, Germany) operating on a Linux platform.

Studies were performed by injecting $1 \mathrm{~mL}$ of the CA suspension $\left(5 \mathrm{mg} \cdot \mathrm{mL}^{-1}\right)$ into the catheterized tail vein as a single bolus $(0.04 \mathrm{mmol} \mathrm{Gd} / \mathrm{kg}$ body weight), and acquiring images $30 \mathrm{~min}$ afterwards. Acquisition was held for $1 \mathrm{~h}$. $T_{2}$-weighted anatomical images to position the animal were collected in the three orthogonal orientations using a rapid acquisition relaxation enhanced sequence (RARE), applying the following parameters: field of view (FOV) $40 \times 40 \mathrm{~mm}, 15$ slices, slice thickness $1 \mathrm{~mm}$, matrix $256 \times 256$, effective echo time $\left(T E_{\text {eff }}\right)=56 \mathrm{~ms}$, repetition time $(T R)=2 \mathrm{~s}, 1$ average and a total acquisition time of $64 \mathrm{~s}[53,54]$. Two types of images were used to assess the effect of CA in the signal intensity in $T_{1}$ - and $T_{2}$-weighted images. For the former, FLASH images were acquired with the following parameters: 25 slices, $1.5 \mathrm{~mm}$ slice thickness, $T R=197 \mathrm{~ms} ; \mathrm{TE}=2.7 \mathrm{~ms} ; \mathrm{FOV}=6.0 \times 5.0 \mathrm{~cm}$; $\operatorname{Mtx}=128 \times 108$; averages $=4$; total acquisition time $=90 \mathrm{~s}$. Three images were acquired before the 
CA administration (baseline) and 20 after it. For the $T_{2}$-weighted images, RARE was used with the same geometry than the $T_{1}$-weighted images and the following parameters: $T R=2800 \mathrm{~ms}$; TE $=48 \mathrm{~ms}$; $\mathrm{FOV}=6.0 \times 5.0 \mathrm{~cm} ; \mathrm{Mtx}=256 \times 214$; averages $=8$; total acquisition time $=600 \mathrm{~s}$. One of these images was acquired at the beginning (baseline) and one at the end of the experiment. Data were analyzed with Image J (W. S. Rasband, U.S. National Institutes of Health, Bethesda, MD, USA).

\section{Conclusions}

Gd-Si oxide nanoparticles obtained by alkaline transformation of a Prussian Blue analogue are a novel MRI contrast agent with higher longitudinal and transversal in vitro relaxivity values than commercial $\mathrm{Gd}^{3+}$ chelate solutions, excellent stability in physiological fluids, no significant cytotoxicity, and easy surface functionalization. These properties prove their potential as a valid alternative to the current CA systems used at the clinical stage, mostly in those cases where the poor pharmacokinetics profile and potential toxicity of $\mathrm{Gd}^{3+}$ soluble forms can become an issue (e.g., patients with renal failure). In this context, future studies will be focused on long-term in vivo stability and potential toxicity of this novel paramagnetic nanocomposite.

Acknowledgments: The authors thank the Spanish MINECO (projects MAT2012-39290-CO2-01 and MAT2012-39290-CO2-02) for financial support. A.C.-G. also thanks "La Caixa" Foundation for a Ph.D. scholarship. We fully appreciate the assistance of the Electron Microscopy Service of the UPV and INSCANNER S.L.

Author Contributions: P.B. and E.F. conceived and designed the experiments. A.C.-G. synthesized and characterized the different contrast agent samples. A.V.-M., A.B. and J.P.-T. performed in vitro and in vivo MRI experiments. E.C.-C. carried out the cytocompatibility study and supervised animals for the in vivo study. A.C.-G. and P.B. prepared the graphic and art work. Finally, A.B., J.P.-T., E.F. and P.B. co-wrote the paper. All authors discussed the results and commented on the manuscript.

Conflicts of Interest: The authors declare no conflict of interest.

\section{References}

1. Bolan, P.J.; Nelson, M.T.; Yee, D.; Garwood, M. Imaging in breast cancer: Magnetic resonance spectroscopy. Breast Cancer Res. 2005, 7, 149-152. [CrossRef] [PubMed]

2. Mitchell, R.E.; Katz, M.H.; McKiernan, J.M.; Benson, M.C. The evaluation and staging of clinically localized prostate cancer. Nat. Rev. Urol. 2005, 2, 356-357. [CrossRef] [PubMed]

3. Zakaria, R.; Das, K.; Bhojak, M.; Radon, M.; Walker, C.; Jenkinson, M.D. The role of magnetic resonance imaging in the management of brain metastases: diagnosis to prognosis. Cancer Imaging 2014, 14. [CrossRef]

4. Cheng, W.; Ping, Y.; Zhang, Y.; Chuang, K.H.; Liu, Y. Magnetic resonance imaging (MRI) contrast agents for tumor diagnosis. J. Healthc. Eng. 2013, 4, 23-45. [CrossRef] [PubMed]

5. Hu, F.; Joshi, H.M.; Dravid, V.P.; Meade, T.J. High-performance nanostructured MR contrast probes. Nanoscale 2010, 2, 1884-1891. [CrossRef] [PubMed]

6. Davis, M.E.; Chen, Z.G.; Shin, D.M. Nanoparticle therapeutics: an emerging treatment modality for cancer. Nat. Rev. Drug Discovery 2008, 7, 771-782. [CrossRef] [PubMed]

7. Lee, N.; Hyeon, T. Designed synthesis of uniformly sized iron oxide nanoparticles for efficient magnetic resonance imaging contrast agents. Chem. Soc. Rev. 2012, 41, 2575-2589. [CrossRef] [PubMed]

8. Hasebroock, Kendra M.; Serkova, Natalie J. Toxicity of MRI and CT contrast agents. Expert Opin. Drug Metab. Toxicol. 2009, 5. [CrossRef] [PubMed]

9. Corot, C.; Robert, P.; Ballet, S.; Gonzalez, W.; Idee, J.-M.; Raynal, I.; Port, M. T1-weighted MR contrast agents for cancer research. In Molecular Imaging Probes for Cancer Research; Chen, X., Ed.; World Scientific Publishing Co. Pte. Ltd.: Singapore, 2012; pp. 611-658.

10. Sun, C.; Lee, J.S.; Zhang, M. Magnetic nanoparticles in MR imaging and drug delivery. Adv. Drug Deliv. Rev. 2008, 60, 1252-1265. [CrossRef] [PubMed]

11. Trewyn, B.G.; Whitman, C.M.; Lin, V.S.-Y. Morphological control of room-temperature ionic liquid templated mesoporous silica nanoparticles for controlled release of antibacterial agents. Nano Lett. 2004, 4, 2139-2143. [CrossRef] 
12. Gao, F.; Botella, P.; Corma, A.; Blesa, J.; Dong, L. Monodispersed mesoporous silica nanoparticles with very large pores for enhanced adsorption and release of DNA. J. Phys. Chem. B 2009, 113, 1796-1804. [CrossRef] [PubMed]

13. Vivero-Escoto, J.L.; Slowing, I.I.; Trewyn, B.G.; Lin, V.S.-Y. Mesoporous silica nanoparticles for intracellular controlled drug delivery. Small 2010, 6, 1952-1967. [CrossRef] [PubMed]

14. Tarn, D.; Ashley, C.E.; Xue, M.; Carnes, E.C.; Zink, J.I.; Brinker, J. Mesoporous silica nanoparticle nanocarriers: biofunctionality and biocompatibility. Acc. Chem. Res. 2013, 46, 792-801. [CrossRef] [PubMed]

15. Karimdjy, M.M.; Tallec, G.; Fries, P.H.; Imbert, D.; Mazzanti, M. Confinement of a tris-aqua Gd(III) complex in silica nanoparticles leads to high stability and high relaxivity and supresses anion binding. 2015, 51, 6836-6838. [CrossRef] [PubMed]

16. Huang, X.; Zhang, F.; Lee, S.; Swierczewska, M.; Kiesewetter, D.O.; Lang, L.; Zhang, G.; Zhu, L.; Gao, H.; Choi, H.S.; et al. Long-term multimodal imaging of tumor draining sentinel lymph nodes using mesoporous silica-based nanoprobes. Biomaterials 2012, 33, 4370-4378. [CrossRef] [PubMed]

17. Davis, J.J.; Huang, W.-Y.; Davies, G.-L. Location-tuned relaxivity in Gd-doped mesoporous silica nanoparticles. J. Mater. Chem. 2012, 22, 22848-22850. [CrossRef] [PubMed]

18. Vivero-Escoto, J.L.; Taylor-Pashow, K.M.L.; Huxford, R.C.; Rocca, J.D.; Okoruwa, C.; An, H.; Lin, W.; Lin, W. Multifunctional mesoporous silica nanospheres with cleavable Gd(III) chelates as MRI contrast agents: synthesis, characterization, target-specificity, and renal clearance. Small 2011, 7, 3519-3528. [CrossRef] [PubMed]

19. Pinho, S.L.; Faneca, H.G.; Geraldes, C.F.; Delville, M.H.; Carlos, L.D.; Rocha, J. Lanthanide-DTPA grafted silica nanoparticles as bimodal-imaging contrast agents. Biomaterials 2012, 33, 925-935. [PubMed]

20. Kim, J.S.; Rieter, W.J.; Taylor, K.M.L.; An, H.; Lin, W.; Lin, W. Self-assembled hybrid nanoparticles for cancer-specific multimodal imaging. J. Am. Chem. Soc. 2007, 129, 8962-8963. [CrossRef] [PubMed]

21. Rieter, W.J.; Kim, J.S.; Taylor, K.M.L.; An, H.; Lin, W.; Tarrant, T.; Lin, W. Hybrid silica nanoparticles for multimodal imaging. Angew. Chem. Int. Ed. 2007, 46, 3680-3682. [CrossRef] [PubMed]

22. Voisin, P.; Ribot, E.J.; Miraux, S.; Bouzier-Sore, A.-K.; Lahitte, J.-F.; Bouchaud, V.; Mornet, S.; Thiaudière, E.; Franconi, J.-M.; Raison, L.; et al. Use of lanthanide-grafted inorganic nanoparticles as effective contrast agents for cellular uptake imaging. Bioconjug. Chem. 2007, 18, 1053-1063. [CrossRef] [PubMed]

23. Taylor, K.M.L.; Kim, J.S.; Rieter, W.J.; An, H.; Lin, W.; Lin, W. Mesoporous silica nanospheres as highly efficient MRI contrast agents. J. Am. Chem. Soc. 2008, 130, 2154-2155. [CrossRef] [PubMed]

24. Guillet-Nicolas, R.; Bridot, J.L.; Seo, Y.; Fortin, M.-A.; Kleitz, F. Enhanced relaxometric properties of MRI "positive" contrast agents confined in three-dimensional cubic mesoporous silica nanoparticles. Adv. Funct. Mater. 2011, 21, 4653-4662. [CrossRef]

25. Karaman, D.Ş.; Desai, D.; Zhang, J.; Tadayon, S.; Unal, G.; Teuho, J.; Sarfraz, J.; Smått, J.-H.; Gu, H.; Näreojaf, T.; et al. Modulation of the structural properties of mesoporous silica nanoparticles to enhance the $T_{1}$-weighted MR imaging capability. J. Mater. Chem. B 2016, 4, 1720-1732. [CrossRef]

26. Chana, M.-H.; Lin, H.-M. Preparation and identification of multifunctional mesoporous silica nanoparticles for in vitro and in vivo dual-mode imaging, theranostics, and targeted tracking. Biomaterials 2015, 46, 149-158. [CrossRef] [PubMed]

27. Zhang, D.; Gao, A.; Xu, Y.; Yin, X.-B.; Hea, X.-W.; Zhangab, Y.-K. Gd-Al co-doped mesoporous silica nanoparticles loaded with $\mathrm{Ru}(\mathrm{bpy})_{3}{ }^{2+}$ as a dual-modality probe for fluorescence and magnetic resonance imaging. Analyst 2014, 139, 4613-4619. [CrossRef] [PubMed]

28. Sharma, P.; Brown, S.C.; Bengtsson, N.; Zhang, Q.; Walter, G.A.; Grobmyer, S.R.; Santra, S.; Jiang, H.; Scott, E.W.; Moudgil, B.M. Gold-speckled multimodal nanoparticles for noninvasive bioimaging. Chem. Mater. 2008, 20, 6087-6094. [CrossRef] [PubMed]

29. Lin, Y.-S.; Hung, Y.; Su, J.-K.; Lee, R.; Chang, C.; Lin, M.-L.; Mou, C.-Y. Gadolinium(III)-incorporated nanosized mesoporous silica as potential magnetic resonance imaging contrast agents. J. Phys. Chem. B 2004, 108, 15608-15611. [CrossRef]

30. Cao, M.; Wang, P.; Kou, Y.; Wang, J.; Liu, J.; Li, Y.; Li, J.; Wang, L.; Chen, C. Gadolinium(III)-chelated silica nanospheres integrating chemotherapy and photothermal therapy for cancer treatment and magnetic resonance imaging. ACS Appl. Mater. Interfaces 2015, 7, 25014-25023. [CrossRef] [PubMed] 
31. Hu, X.; Wang, M.; Miao, F.; Ma, J.; Shena, H.; Jia, N. Regulation of multifunctional mesoporous core-shell nanoparticles with luminescence and magnetic properties for biomedical applications. J. Mater. Chem. B 2014, 2, 2265-2275. [CrossRef]

32. Huang, S.; Cheng, Z.; Ma, P.; Kang, X.; Daia, Y.; Lin, J. Luminescent GdVO 4 :Eu ${ }^{3+}$ functionalized mesoporous silica nanoparticles for magnetic resonance imaging and drug delivery. Dalton Trans. 2013, 42, 6523-6530. [CrossRef] [PubMed]

33. Shao, Y.; Tian, X.; Hu, W.; Zhang, Y.; Liu, H.; He, H.; Shen, Y.; Xie, F.; Li, L. The properties of Gd ${ }_{2} \mathrm{O}_{3}$-assembled silica nanocomposite targeted nanoprobes and their application in MRI. Biomaterials 2012, 33, 6438-6446. [CrossRef] [PubMed]

34. Cho, H.K.; Cho, H.-J.; Lone, S.; Kim, D.-D.; Yeum, J.H.; Cheong, I.W. Preparation and characterization of MRI-active gadolinium nanocomposite particles for neutron capture therapy. J. Mater. Chem. 2011, 21, 15486-15493.

35. Hu, K.-W.; Jhang, F.-Y.; $\mathrm{Su}$, C.-H.; Yeh, C.-S. Fabrication of $\mathrm{Gd}_{2} \mathrm{O}\left(\mathrm{CO}_{3}\right)_{2} \cdot \mathrm{H}_{2} \mathrm{O} /$ silica/gold hybrid particles as a bifunctional agent for MR imaging and photothermal destruction of cancer cells. J. Mater. Chem. 2009, 19, 2147-2153. [CrossRef]

36. Xing, H.; Bu, W.; Zhang, S.; Zheng, X.; Lic, M.; Chen, F.; Hea, Q.; Zhou, L.; Peng, W.; Hua, Y.; et al. Multifunctional nanoprobes for upconversion fluorescence, MR and CT trimodal imaging. Biomaterials 2012, 33, 1079-1089. [CrossRef] [PubMed]

37. Yeh, C.-S.; Su, C.-H.; Ho, W.-Y.; Huang, C.-C.; Chang, J.-C.; Chien, Y.-H.; Hung, S.-T.; Liau, M.-C.; Ho, H.-Y. Tumor targeting and MR imaging with lipophilic cyanine-mediated near-infrared responsive porous $\mathrm{Gd}$ silicate nanoparticles. Biomaterials 2013, 34, 5677-5688. [CrossRef] [PubMed]

38. Cabrera-García, A.; Vidal-Moya, A.; Bernabeu, A.; Sánchez-González, J.; Fernández, E.; Botella, P. Gd-Si oxide mesoporous nanoparticles with pre-formed morphology prepared from a Prussian blue analogue template. Dalton Trans. 2015, 44, 14034-14041. [CrossRef] [PubMed]

39. Perrier, M.; Kenouche, S.; Long, J.; Thangavel, K.; Larionova, J.; Goze-Bac, C.; Lascialfari, A.; Mariani, M.; Baril, N.; Guérin, C.; et al. Investigation on NMR relaxivity of nano-sized cyano-bridged coordination polymers. Inorg. Chem. 2013, 52, 13402-13414. [CrossRef] [PubMed]

40. Zhang, L.; Wu, H.B.; Lou, X.W. Metal-organic-frameworks-derived general formation of hollow structures with high complexity. J. Am. Chem. Soc. 2013, 135, 10664-10672. [CrossRef] [PubMed]

41. Zhang, L.; Wu, H.B.; Madhavi, S.; Hng, H.H.; Lou, X.W. Formation of $\mathrm{Fe}_{2} \mathrm{O}_{3}$ Microboxes with hierarchical shell structures from metal-organic frameworks and their lithium storage properties. J. Am. Chem. Soc. 2012, 134, 17388-17391. [CrossRef] [PubMed]

42. Engström, M.; Klasson, A.; Pedersen, H.; Vahlberg, C.; Per-Olov, K.; Uvdal, K. High proton relaxivity for gadolinium oxide nanoparticles. Magn. Reson. Mater. Phy. 2006, 19, 180-186. [CrossRef] [PubMed]

43. Osseni, S.A.; Lechevallier, S.; Verelst, M.; Perriat, P.; Dexpert-Ghys, J.; Neumeyer, D.; Garcia, R.; Mayer, F.; Djanashvili, K.; Peters, J.A.; et al. Gadolinium oxysulfide nanoparticles as multimodal imaging agents for $T_{2}$-weighted MR, X-ray tomography and photoluminescence. Nanoscale 2014, 6, 555-564. [CrossRef] [PubMed]

44. Mahmoudi, M.; Lynch, I.; Ejtehadi, M.R.; Monopoli, M.P.; Bombelli, F.B.; Laurent, S. Protein-Nanoparticle interactions: opportunities and challenges. Chem. Rev. 2011, 111, 5610-5637. [CrossRef] [PubMed]

45. Clemments, A.M.; Muniesa, C.; Landry, C.C.; Botella, P. Effect of surface properties in protein corona development on mesoporous silica nanoparticles. RSC Adv. 2014, 4, 29134-29138. [CrossRef]

46. Lu, J.; Liong, M.; Li, Z.; Zink, J.I.; Tamanoi, F. Biocompatibility, biodistribution, and drug-delivery efficiency of mesoporous silica nanoparticles for cancer therapy in animals. Small 2010, 6, 1794-1805. [CrossRef] [PubMed]

47. Botella, P.; Abasolo, I.; Fernández, Y.; Muniesa, C.; Miranda, S.; Quesada, M.; Ruiz, J.; Schwartz, S., Jr.; Corma, A. Surface-modified silica nanoparticles for tumor-targeted delivery of camptothecin and its biological evaluation. J. Control. Release 2011, 10, 246-257. [CrossRef] [PubMed]

48. Na, H.B.; Lee, J.H.; An, K.; Park, Y.I.; Park, M.; Lee, I.S.; Nam, D.-H.; Kim, S.T.; Kim, S.-H.; Kim, S.-W.; et al. Development of a $T_{1}$ contrast agent for magnetic resonance imaging using $\mathrm{MgO}$ nanoparticles. Angew. Chem. Int. Ed. 2007, 46, 5397-5401. [CrossRef] [PubMed] 
49. Kim, T.; Cho, E.-J.; Chae, Y.; Kim, M.; Oh, A.; Jin, J.; Lee, E.-S.; Baik, H.; Haam, S.; Suh, J.-S.; et al. Urchin-shaped manganese oxide nanoparticles as $\mathrm{pH}$-responsive activatable $T_{1}$ contrast agents for magnetic resonance imaging. Angew. Chem. Int. Ed. 2011, 50, 10589-10593. [CrossRef] [PubMed]

50. Lim, E.-K.; Kim, T.; Paik, S.; Haam, S.; Huh, Y.-M.; Lee, K. Nanomaterials for theranostics: Recent advances and future challenges. Chem. Rev. 2015, 115, 327-394. [CrossRef] [PubMed]

51. Maschrak, P.K. Convenient synthesis of tris(tetraethylammonium) hexacyanoferrate(III) and its use as an oxidant with tunable redox potential. Inorg. Chem. 1986, 25, 245-247. [CrossRef]

52. Blüml, S.; Schad, L.R.; Stepanow, B.; Lorenz, W.J. Spin-lattice relaxation time measurement by means of a TurboFLASH technique. Magn. Reson. Med. 1993, 30, 289-295. [CrossRef] [PubMed]

53. Hennig, J.; Friedburg, H. Clinical applications and methodological developments of the RARE technique. Magn. Reson. Imaging 1988, 6, 391-395. [CrossRef]

54. Hennig, J.; Nauerth, A.; Friedburg, H. RARE imaging: a fast imaging method for clinical MR. Magn. Reson. Med. 1986, 3, 823-833. [CrossRef] [PubMed]

(C) 2016 by the authors; licensee MDPI, Basel, Switzerland. This article is an open access article distributed under the terms and conditions of the Creative Commons Attribution (CC-BY) license (http://creativecommons.org/licenses/by/4.0/). 